\title{
A REVIEW OF "NON-STATIONARY TIME SERIES ANALYSIS AND COINTEGRATION" BY COLIN P. HARGREAVES*
}

\author{
Francisco G. Carneiro**
}

The book is addressed to both professional economists who believe in econometrics and graduate students with a taste for time series analysis. It discusses important features of the increasingly popular method of cointegration analysis and non-stationary time series blending the theoretical discussion with detailed implementations which appear quite helpful to practitioners. Common questions such as how to determine the lag length in a Johansen VAR, or what treatment to give to a second valid cointegrating vector are dealt with in this book, which is another volume of the excellent series Advanced Texts in Econometrics, edited by Granger and Mizon. In this volume, Collin Hargreaves gathers ten articles showing major developments in the econometric analysis of long-run relationships and model evaluation. The papers discuss in depth the problems involved with, and the new methods related to, the analysis of non-stationary time series and cointegration. The authors ivlio contribute to the book not only address the technical details but also give a fair dimension of how the subject matter has so profoundly affected recent econometric analysis in general.

The first chapter (Towards a Theory of Economic Forecasting) is authored by Michael P. Clements and David F. Hendry, and discusses recent developments in the theory of economic forecasting using econometric models. A comprehensive list of sources of forecast errors is analyzed, including parameter non-constancy, estimation uncertainty, variable uncertainty, innovation uncertainty, and model misspecification. The authors also propose a theory of intercept adjustment to mitigate these errors and show the potential advantages

*Hargrcaves, Colin, P. Non-Slalionary Time Series Analysis and Cointegralion. Advanced Texts in Econometrics, 308 pp. Oxford: Oxford University Press, 1991. **Department of Economics, Kcynes College, University of Kent at Canterbury - UK.

R. de Econometria Rio de Janeiro v. 11, n² 2, p.257-260 novembro 1991/março 1995 
of combining types of forecast to improve accuracy but alert to the problems of pooling rival econometric models. A positive aspect of the paper is that it shows where econometrics could actually contribute to improve forecasting in a context of frequent changes in the data generating process and in a world where analysts are often disagreeing about the best model to use.

The second chapter (Bayes Models and Forecasts of Australian Macroeconomic Time Series) authored by Peter Phillips also addresses forecasting performance but focuses on the issue of evaluating different models. The author also provides a data-based approach to deal with the problem of separately determining lag length from cointegrating rank in the Joliansen reduced rank regression method and suggests the use of the same criterion to determine lag order, parameter constancy, and the presence of deterministic and stochastic trends. The paper concludes emphasizing the best forecasting performance of "Bayes models" over the rival models (basically AR $(\cdot)$ plus a linear trend) in a forecasting exercise using quarterly Australian macroeconomic time series. All the models considered in the paper, however, are univariate, but the ideas employed can be extended to multivariate time series, although there tistical theor' $y^{\prime}$

There are then four papers discussing different techniques for estimating cointegrating relations. In chapter 4 (A Review of Methods of Estimating Cointegration Relationships), Colin Hargreaves compares six estimators of cointegrating relations: OLS, Augmented OLS, Fully-Modified, Three-Step, Johansen MLE, and Box-Tiao. The Joliansen estimator was found to be the best as long as the sample was large (around 100 observations) and the model appropriately specified. The author addresses a question which is usually left apart by most practitioners: how to present properly the case where there are two or more valid cointegrating vectors. The procedure suggested is to use the Joliansen estimator to determine the cointegrating rank of the sy'stem, and then the cointegrating vectors with the OLS method pulling out the number of vectors determined by the Johansen test. Of course, it presupposes that the researcher knows a priori how many vectors to expect; the whole idea behind this proce- 
dure is the easy treatment of the subsequent estimated cointegrating vectors.

David Harris and Brett Inder are responsible for chapter 5 ( $A$ Test of the Null Hypothesis of Cointegration) which focuses on testing for cointegration. The authors support the view that it may be preferable to test a null of stationarity rather than the ADF null of nonstationarity when investigating if a series has unit roots or not. Their approach involves including explanatory variables to test the null of cointegration as opposed to the traditional Augmented DickeyFuller null of no cointegration.

The remaining two papers on cointegration deal with the issue . of seasonal integration. In chapter 6 (Modelling Seasonal Variation), Svend Hylleberg develops several examples to assess a number of methods of testing for seasonal cointegration. Chapter 7 (Cointegration, Seasonality, Encompassing, and the Demand for Money in the UK) is jointly authored by Neil Ericsson, David Hendry and rongAnh Tran. In this paper, the authors try to establish theoretical and empirical relationships between seasonally adjusted and unadjusted data while describing encompassing tests to compare models which used each type of data. There is also an interesting and detailed example of an application of Hendry's general-to-specific type of modelling to the case study of the demand for money in the United Kingdom.

In chapter 8 (Evaluating a Real Business Cycle Model), Fabio Canova, Mary Finn and Adrian Pagan argue that the usual procedure of assessing a model by its power to explain stylised facts is not extensive enough and so they propose to evaluate a model using standard econometric procedures. It is argued that a model is best evaluated through the comparison of its restricted VAR representation with the VAR estimated in "an unrestricted way from the underlying data", to use the authors' words.

Chapter 9 (Misspecification versus Bubbles in the Cagan Hyperinflation Model) by Steven Durlauf and Mark Hooker addresses an issue which is usually superficially treated in the literature: how to test for model specification separately from the presence of bubbles in Cagan hyperinflation type of models. Finally, in chap- 
ter 10 (Regime Switching with Time-Varying Transition Probabilities), Francis Diebold, John-Haeng Lee and Gretchen Weinbach extend the Markov switching model to study recurrent regime shifts in a simple dynamic econometric model using a class of Markov switching models in which the transition probabilities are endogenous (that is, they can vary with the fundamentals). As a result, they found, along the same lines of Durlauf and Hooker, that sudden changes in regime may be rather related to underlying economic fundamentals instead of being constant.

In sum, the book is an excellent choice for those interested in non-stationary time series and the analysis of cointegration. This collection of papers provides a careful overview of the theme and contributes for the cause of using appropriately new econometric understanding in the field of policy making. It is also a good source for those who want to follow the fast development of issues such as the separation of long-run relationships from short-term dynamics and the identification of an economic system. 